\title{
Runx2 Controls Bone Resorption through the Down-Regulation of the Wnt Pathway in Osteoblasts
}

\author{
Coline Haxaire, ${ }^{* \dagger}$ Eric Haÿ, ${ }^{* \dagger}$ and Valérie Geoffroy ${ }^{* \dagger}$
}

From Inserm UMR_S1132 BIOSCAR, * Lariboisiere Hospital, Paris; and the University Paris Diderot ${ }^{\dagger}$ Sorbonne Paris City, Paris, France

\author{
Accepted for publication \\ January 21, 2016. \\ Address correspondence to \\ Valérie Geoffroy, Ph.D., Inserm \\ UMR_S1132 BIOSCAR, Hôpi- \\ tal Lariboisière, Centre Viggo \\ Petersen, 2 rue Ambroise Paré, \\ 75010 Paris, France. E-mail: \\ valerie.geoffroy@inserm.fr.
}

\begin{abstract}
The transcription factor Runx2 and the Wnt/ $\beta$-catenin pathway are major regulators of bone formation. Our aim was to assess the interactions between the Wnt/ $\beta$-catenin pathway and Runx 2 that contribute to bone resorption. Our results indicate that the activity of the canonical Wnt/ $\beta$-catenin pathway depends on Runx2. Runx2 overexpression inhibited $\beta$-catenin levels and activity in vitro and in vivo. Inhibition of Gsk3b using lithium chloride in Runx2-overexpressing osteoporotic female mice rescued the $\mathrm{Wnt} / \beta$-catenin signaling in vivo and completely restored trabecular bone volume by increasing bone formation and decreasing bone resorption. The activation of $W n t / \beta$-catenin signaling by lithium chloride treatment reduced the number and activity of bone marrow-derived osteoclast-like cells in vitro, suggesting that the restoration of trabecular bone in vivo was due to decreased bone resorption, consistent with the reduced receptor activator of NF- $\kappa \mathrm{B}$ ligand/osteoprotegerin ratio in Runx2-overexpressing osteoblasts. Lithium chloride also increased osteoblast differentiation and activity in vitro in agreement with the increase in mineral apposition rate and osteocalcin expression detected in vivo. Our results indicate that the activity of the canonical Wnt/ $\beta$-catenin pathway in osteoblast is modulated by Runx2. To conclude, our in vivo and in vitro results highlight the role of Runx2 as a negative regulator of Wnt/ $\beta$-catenin pathway activity in osteoblasts and indicate that the abnormal Wnt/ $\beta$-catenin activity seen in Runx2 transgenic mice affects both osteoblast and osteoclast differentiation and activity. (Am J Pathol 2016, 186: 1598-1609; http://dx.doi.org/ 10.1016/j.ajpath.2016.01.016)
\end{abstract}

The canonical Wnt/ $\beta$-catenin signaling pathway is essential for osteoblast differentiation, ${ }^{1,2}$ bone formation, and bone mass. ${ }^{3} \mathrm{Wnt} / \beta$-catenin signaling requires the interaction of secreted Wnt proteins with the Frizzled receptor and coreceptors LRP5/6, which leads to the inhibition of the adenomatosis polyposis coli (Apc)-glycogen synthase kinase $3 \beta$ (Gsk3b)-axin complex. This, in turn, inhibits the phosphorylation of $\beta$-catenin and its subsequent degradation by the proteasome. Consequently, â-catenin accumulates in the cytosol, translocates into the nucleus, and binds to its co-factors Tcf and Lef to activate the transcription of specific target genes. ${ }^{4,5}$ Osteoporosis-pseudoglioma syndrome, resulting from loss-of-function mutations in the LRP5 gene, represents the most striking evidence for the importance of normal $\mathrm{Wnt} / \beta$-catenin signaling for bone homeostasis. ${ }^{6,7}$ In osteoblasts, the Wnt/ $\beta$-catenin pathway also controls the expression of osteoprotegerin (Opg), the potent and specific inhibitor of receptor activator of $N F-\kappa B$ ligand (Rankl)-induced osteoclastogenesis, and via this mechanism also contributes to the regulation of osteoclast

Supported by Institut National de la Santé et de la Recherche Médicale grant DVO20081013482 from the Fondation pour la Recherche Médicale, and grant NR-08-GENOPAT-009 [Role of Dlx5 and Runx2 in osteoporosis (DRos)] from the Agence Nationale de la Recherche (V.G.). C.H. was a recipient of a Ph.D. award from the Ministère de la Recherche (Paris, France).

Disclosures: None declared.

Portions of this work were presented in an oral presentation at the American Society for Bone and Mineral Research Annual Meeting; September 16-20, 2011; San Diego, CA; and as a poster at the European Calcified Tissue Society Annual Congress; May 19-23, 2012; Stockholm, Sweden.

Current address of C.H., Hospital for Special Surgery, New York, NY. 
differentiation and bone resorption. ${ }^{8}$ Furthermore, the Wnt/ $\beta$-catenin axis regulates Runx 2 expression in mesenchymal cells, thus controlling osteoblast differentiation and skeletal development. ${ }^{9}$

Runx2, also known as Cbfa1, is a member of the Runt domain gene family and is essential for osteoblast development and bone formation. Runx 2 drives pluripotent mesenchymal cells to the osteoblast lineage and increases their maturation and function ${ }^{10-12}$ by regulating the expression of several osteoblast-related extracellular matrix proteins in osteoblasts, including osteocalcin. ${ }^{13-15}$ In humans, a RUNX2 null mutation results in cleidocranial dysplasia in humans, a condition defined by the absence or a reduction of collarbones and delayed closure of the sutures of the skull. ${ }^{16,17}$ Furthermore, Runx2-deficient mice die at birth and have a cartilaginous skeleton associated with the absence of osteoblasts, highlighting the major role of Runx2 in bone patterning and endochondral and intramembranous ossification. ${ }^{16}$ We and others have found that Runx 2 overexpression under the control of the Collal promoter results in a notable reduction of bone mass and bone volume, leading to the development of spontaneous fractures. ${ }^{18,19}$ Runx2-overexpressing mice have been characterized by an alteration in the final steps of osteoblast maturation. This alteration is accompanied by increased osteoclast differentiation and activity associated with a higher Rankl/Opg ratio, ${ }^{19}$ which is consistent with the role of Runx 2 as a direct regulator of Rankl and Opg expression in vitro. ${ }^{20,21}$

In this study, we tested whether the marked increase in bone resorption observed in transgenic (TG) Runx2 mice is attributable to osteoblast-intrinsic defects in canonical Wnt/ $\beta$-catenin signaling. Our results provide strong evidence of the regulation of osteoblast-mediated bone resorption via the interaction between Runx 2 and the canonical Wnt/ $\beta$-catenin signaling pathway.

\section{Materials and Methods}

\section{Animal and Experimental Protocol}

Mice that overexpress Runx2 were created as previously described (Supplemental Figure S1). ${ }^{19}$ The mice were housed under controlled conditions at $24^{\circ} \mathrm{C}$ on a 12 -hour light/12-hour dark cycle. Female Runx2 overexpressing mice involved in the study were obtained by mating $\mathrm{TG}$ male $\mathrm{C} 57 \mathrm{BL} / 6 \times \mathrm{BALB} / \mathrm{c}$ mice from the seventh generation with female C57BL/6 $\times$ BALB/c F1 mice (Harlan, Hong Kong). Eight-week-old TG Runx2 females and their wildtype (WT) littermates (CB6F) were used for this study. Mice received by oral route either lithium chloride $(\mathrm{LiCl})$ at $200 \mathrm{mg} / \mathrm{kg}$ or vehicle (water) 5 days per week for four weeks. The $\mathrm{LiCl}$ concentration was adjusted weekly to ensure that the mice received a daily dose of $200 \mathrm{mg} / \mathrm{kg}$. To evaluate the dynamic bone formation parameters by histomorphometry, mice received two fluorochromes by i.p. injection [5 days before necropsy, $20 \mathrm{mg} / \mathrm{kg}$ of oxytetracycline (Pfizer, Amboise, France), and 1 day before necropsy, $20 \mathrm{mg} / \mathrm{kg}$ of calcein (Sigma-Aldrich, St. Louis, MO)].

TopGal female mice [STOCK Tg(Fos-lacZ)34Efu/J (JAX, Bar Harbor, ME)], in which the $\beta$-galactosidase gene was under the control of LEF/TCF and $\beta$-catenin inducible promoter, were used to quantify $\beta$-catenin transcriptional activity. ${ }^{22}$ TopGal female mice were crossed with males that overexpress Runx2 or Runx $2^{+/-} .17 \mathrm{TG} /$ TopGal and Runx $2^{+/-} /$TopGal mice were used to evaluate the effects of Runx2 overexpression and haploinsufficiency on the activity of the Wnt pathway. Respective WT/TopGal mice were used as controls. All animal procedures have been approved by the Ethical Committee LariboisiereVillemin (approval CRRALV/2010-03-01).

\section{Histology and Histomorphometry}

After dissection, femurs of WT and TG Runx2 females treated with vehicle control or $\mathrm{LiCl}$ were processed for histomorphometric analysis. Femurs were fixed in $70 \%$ ethanol and embedded in methyl methacrylate. Sections obtained with a Leica microtome (SM2500S) (Wetzlar, Germany) were stained with naphthol ASTR (3hydroxy-2naphthoic acid 4-chloro-2-methylanilide) phosphate for tartrate-resistant acid phosphatase (Trap) detection or with toluidine blue. The trabecular bone volume (BV/TV), trabecular number (Tb.N), trabecular separation (Tb.Sp), and trabecular thickness (Tb.Th) were measured using a Bonolab/histolab software package version 1.0 developed for bone histomorphometry (Microvision, Evry, France). The histomorphometric parameters were recorded in compliance with the recommendation of the American Society for Bone and Mineral Research Histomorphometry Nomenclature Committee. ${ }^{23}$ Osteoclast surface and number were determined on Trap-stained sections using a Leitzintegrateplatte II eyepiece at $\times 128$ magnification. The dynamic parameters were measured in $12-\mu \mathrm{m}$-thick, unstained sections examined under UV light. The mineral apposition rate (MAR) was measured using the same image analyzer (Microvision) by a semiautomatic method on calcein/tetracycline double-labeled surfaces. The mineralizing surfaces were measured in the same areas using the objective eyepiece Leitzintegrateplatte II. The bone formation rate was calculated according to the published nomenclature. All parameters were measured and calculated in compliance with the recommendation of Parfitt et al. ${ }^{23}$

\section{Culture of Primary 0steoblasts and 0steoclasts}

Primary osteoblasts were isolated from the calvaria of 2- to 4-day-old WT and TG mice. Calvaria were sequentially digested for 15 minutes in phosphate-buffered saline (PBS) $1 \times$ that contained $0.2 \%$ type IV collagenase with EDTA to remove fibroblasts and for 45 minutes in PBS $1 \times$ that contained $0.2 \%$ type IV collagenase to collect osteoblastic 
cells. Cells were expanded for 5 to 6 days in minimum essential medium $\alpha$-containing $10 \%$ fetal bovine serum and plated at a density of $2.5 \times 10^{+4}$ cells $/ \mathrm{cm}^{2}$. After reaching confluency (at approximately 3 days), the medium was supplemented with $50 \mu \mathrm{M}$ ascorbic acid and $100 \mu \mathrm{M} \beta$ glycerophosphate, which was replaced every 2 to 3 days. For the determination of alkaline phosphatase activity, cells were plated at $4 \times 10^{+4}$ cells per well in 24 -well plates. For RNA extraction and the evaluation of mineralization, cells were plated at $2 \times 10^{+5}$ cells per well in 6 -cm plates and for protein extraction at $1 \times 10^{+6}$ cells per plate in $10-\mathrm{cm}$ plates. For evaluation of cell proliferation, cells were plated at 7000 cells per well in 96-well plates and treated as indicated. One day after plating, cells were treated with Wnt3a, LiCl, and SB216763 (Sigma-Aldrich), and incorporation of 5-bromo-2'-deoxyuridine (BrdU) was performed for a 12-hour period 6 hours after treatment. Cell proliferation was determined by colorimetric absorbance (optical density) using the BrdU enzyme-linked immunosorbent assay (Roche, Paris, France).

Bone marrow (BM) cells were aseptically collected from femur and tibia, depleted of red blood cell in a lysate buffer $\left(155 \mathrm{mmol} / \mathrm{L} \quad \mathrm{NH}_{4} \mathrm{Cl} ; 10 \mathrm{mmol} / \mathrm{L} \mathrm{KHCO}_{3} ; 0.1 \mathrm{mmol} / \mathrm{L}\right.$ EDTA; pH 7.4) and plated in minimum essential medium $\alpha$-containing $10 \%$ fetal bovine serum in 8 -well Labtek slides $\left(8 \times 10^{+5}\right.$ cells per well) for Trap staining, in 1-well Labtek slides $\left(5 \times 10^{+6}\right.$ cells per well $)$ for total RNA isolation, and in 96-well plates (105 cells per well on dentine slice) for the determination of osteoclast activity. At day 1 , osteoblast differentiation was induced with $50 \mu \mathrm{M}$ ascorbic acid and $10^{-8} \mathrm{M}$ dihydroxyvitamin $\mathrm{D}_{3}$ $\left[1,25(\mathrm{OH})_{2} \mathrm{D}_{3}\right]$ (started at day 5). Half of the medium was replaced every other day for 11 days. At the end of the culture period, the cells were washed with PBS, fixed with 4\% paraformaldehyde, stained for Trap (Trap staining kit 387A; Sigma-Aldrich), and nuclear counterstained with methyl green solution. Trap-positive multinucleated (number of nuclei $>3$ ) cells were considered osteoclasts and were counted under the microscope.

\section{Dual-Energy X-ray Absorptiometry and Micro-Computed Tomography}

Dual-energy X-ray absorptiometry analysis of all animals was performed with the animals under anesthesia. Femur bone mineral density (BMD) was measured using a PIXImus instrument (software version 1.44; PIXImus, Lunar, France). An ultrahigh resolution mode (resolution of $0.18 \times$ $0.18 \mathrm{~mm}$ ) was used. The coefficient of variation was $<2 \%$ for all evaluated parameter. A phantom was scanned daily to monitor the stability of the measurements.

Tibias were analyzed with high-resolution microcomputed tomography (micro-CT) using a Skyscan 1172 scanner (Skyscan, Aartselaar, Belgium). These qualitative and quantitative imaging analyses were mainly focused on the proximal metaphysis of the tibias. The radiographic projections $(n=210)$ were acquired at $80 \mathrm{kV}$ and $100 \mu \mathrm{A}$ with an exposure time of $100 \mathrm{~ms}$ and a $0.5-\mathrm{mm}$ aluminum filter. Ten frames were averaged for each rotation increment of $0.5^{\circ}$ to increase the signal-to-noise ratio. Threedimensional (3D) images were reconstructed with a mean voxel size of $6 \mu \mathrm{m}$, using the manufacturer's reconstruction software NRecon version 1.6.2.0 (Skyscan, Bruker microCT, Kontich, Belgium). For quantitative analysis, the resident software CTAn version 1.10.1.0 (Skyscan, Bruker microCT) was used to obtain the following measurements within the volume of interest: $\mathrm{BV} / \mathrm{TV}_{3 \mathrm{D}}, \mathrm{Tb} . \mathrm{N}_{3 \mathrm{D}}, \mathrm{Tb} . \mathrm{Sp}_{3 \mathrm{D}}$, and Tb.Th.3D. The 3D model images were reconstructed and merged from the section stack with the resident software CTVol version 1.11.1.0 (Skyscan, Bruker microCT).

\section{$\beta$-Galactosidase Staining}

Femurs from 3-month-old WT and TG female mice were fixed in $2 \%$ paraformaldehyde and $0.02 \%$ glutaraldehyde for 3 hours at room temperature. Decalcification was performed in $4 \%$ EDTA for 2 weeks, and bones were stored in optimum cutting temperature mounting medium (Labonord, Lille, France). Seven-micrometer femur sections were incubated at $37^{\circ} \mathrm{C}$ overnight in X-Gal solution $[100 \mathrm{mmol} / \mathrm{L}$ sodium phosphate, $\mathrm{pH} 7.3,77 \mathrm{mmol} / \mathrm{L} \quad \mathrm{Na}_{2} \mathrm{HPO}_{4}$, $23 \mathrm{mmol} / \mathrm{L} \mathrm{NaH} \mathrm{PO}_{4}, 1.3 \mathrm{mmol} / \mathrm{L} \mathrm{MgCl}_{2}, 3 \mathrm{mmol} / \mathrm{L}$ potassium ferricyanide $\left(\mathrm{K}_{3} \mathrm{Fe}[\mathrm{CN}]_{6}\right), 3 \mathrm{mmol} / \mathrm{L}$ potassium ferrocyanide $\left(\mathrm{K}_{4} \mathrm{Fe}[\mathrm{CN}]_{6}\right), 1 \mathrm{mg} / \mathrm{mL}$ of $\left.\mathrm{X}-\mathrm{Gal}\right]$, washed with water, and counterstained with eosin. ${ }^{24}$

Calvaria isolated from newborn WT, WT/TopGal, TG/ TopGal, or Runx $2^{+/} /$TopGal were fixed in $2 \%$ paraformaldehyde and $0.02 \%$ glutaraldehyde for 40 minutes at $4^{\circ} \mathrm{C}$.

After 3 days of culture, primary osteoblasts were fixed in $2 \%$ paraformaldehyde and $0.02 \%$ glutaraldehyde for $3 \mathrm{mi}-$ nutes, at $4^{\circ} \mathrm{C}$, washed twice with PBS, and incubated at $30^{\circ} \mathrm{C}$ overnight in $\mathrm{X}$-Gal solution.

\section{Isolation of Total RNA, RT-PCR, and Real-Time Quantitative PCR}

Total RNA was isolated from the metaphysis of tibiae and femurs or from primary osteoblasts in culture using Trizol reagent (Invitrogen, Carlsbad, CA). RNA samples were further cleaned using the RNeasy mini kit (Qiagen, Valencia, CA) according to the manufacturer's instructions. Total RNA was then reverse transcribed $(1 \mu \mathrm{g}$ per sample) into cDNA using a cDNA Verso Kit (Abgene, Epsom, UK). Real-time quantitative PCR (qPCR) expression analysis was performed on a Light Cycler 480 (Roche Diagnostics, Indianapolis, IN) using ABsolute Blue qPCR SYBR Green mix (Abgene) at $60^{\circ} \mathrm{C}$ for 40 cycles. Primers were designed from the online mouse probes library (Roche Diagnostics). Hprt, Sdha, and Tbp were used as housekeeping genes. Primer sequences are provided in Table 1. 
Table 1 Primer Sequences Used for qPCR Amplification

\begin{tabular}{|c|c|c|c|}
\hline Gene & Primers sequence for $\mathrm{qPCR}$ amplification & Direction & NT \\
\hline \multirow[t]{2}{*}{ Tbp } & 'CACGGACAACTGCGTTGATTT-3' & Forward & 21 \\
\hline & 5'-GCTGCTAGTCTGGATTGTTCTTCA-3' & verse & 24 \\
\hline \multirow[t]{2}{*}{ Hprt } & $5^{\prime}$-GTTGGATATGCCCTTGACTATAATGA-3' & Forward & 26 \\
\hline & $5^{\prime}$-CAACATCAACAGGACTCCTCGTATT- $3^{\prime}$ & everse & 25 \\
\hline \multirow[t]{2}{*}{ Sdha } & $5^{\prime}-$ TGGACATCAAGACTGGCAAGG-3' & Forward & 21 \\
\hline & $5^{\prime}$-CAGTAGGAGCGGATAGCAGGAG- $3^{\prime}$ & rse & 22 \\
\hline \multirow[t]{2}{*}{ Opg } & 5'-CATCTGGACATTTTTTGCAAA-3' & Forward & 21 \\
\hline & $5^{\prime}$-AGTCGGTGAAGCAGGAGTG-3' & rse & 19 \\
\hline \multirow[t]{2}{*}{ Col1a1 } & 5'-CTTGGTGGTTTTGTATTCGATGAC-3' & Forward & 24 \\
\hline & $5^{\prime}$-GCGAAGGCAACAGTCGCT-3' & arse & 18 \\
\hline \multirow{2}{*}{$\begin{array}{l}O C \\
\qquad \text { (Bglap) }\end{array}$} & $5^{\prime}$-CTCACAGATGCCAAGCCCA-3' & Forward & 19 \\
\hline & $5^{\prime}$-CCAAGGTAGCGCCGGAGTCT-3' & erse & 20 \\
\hline \multirow[t]{2}{*}{ Rankl } & 5'-AGTGACTTTATGGGAACCCGAT- & Forward & 22 \\
\hline & $5^{\prime}$-GGCCACAGCGCTTCTCAG-3' & Reverse & 18 \\
\hline \multirow{2}{*}{$\begin{array}{l}\text { TRACP } \\
\qquad(A c p 5)\end{array}$} & 5'-CGTCTCTGCACAGATTGCAT-3' & Forward & 20 \\
\hline & $5^{\prime}$-AAGCGCAAACGGTAGTAAGG-3' & Reverse & 20 \\
\hline
\end{tabular}

NT, nucleotide; $q P C R$, real-time quantitative PCR.

\section{$\beta$-Catenin Reporter Activity}

Primary osteoblasts were isolated from TopGal WT and TG Runx2 newborn mice as described above. Cells were plated in 24-well plates $\left(4 \times 10^{+5}\right.$ cells per well) and incubated for 3 days. Cells were scraped into Reporter Lysis Buffer (Promega, Madison, WI), and $\beta$-galactosidase activity was determined quantitatively using a chemiluminescent assay kit ( $\beta$-Gal reporter gene assay; Roche) and expressed as units per milligram of protein.

\section{Protein Extractions and Western Blotting}

For total protein extraction, cells were scraped in lysate buffer [50 mmol/L Tris; $150 \mathrm{mmol} / \mathrm{L} \mathrm{NaCl}$; NP-40 1\%; glycerol $10 \%$ with protease inhibitor (Roche)]. Cytoplasmic and nuclear proteins were extracted as previously described. ${ }^{25}$ Briefly, cells were scraped in cold phosphate-buffered saline, centrifuged at $12,000 \times g$ for 30 seconds, and resuspended in $400 \mu \mathrm{L}$ of buffer A (10 mmol/L HEPES, $\mathrm{pH} 7.9$; $1.5 \mathrm{mmol} / \mathrm{L} \mathrm{MgCl}_{2} ; 10 \mathrm{mmol} / \mathrm{L} \mathrm{KCl}$ ) with $25 \mu \mathrm{L}$ of $10 \% \mathrm{NP}-$ 40. After centrifugation, the cytoplasmic fraction was collected, and the pellet that contained the nuclei was resuspended in buffer B (20 mmol/L HEPES, pH 7.9; $25 \%$ glycerol; $1.5 \mathrm{mmol} / \mathrm{L} \mathrm{MgCl}_{2} ; 0.2 \mathrm{mmol} / \mathrm{L}$ EDTA; $0.46 \mathrm{M} \mathrm{NaCl}$ ). For Western blot analysis, 20 to $30 \mu \mathrm{g}$ of proteins per lane were separated by $6 \%$ or $10 \%$ SDS-PAGE and transferred to polyvinylidene difluoride membranes (GE Healthcare, Little Chalfont, UK). The proteins of interest were detected using specific primary antibodies raised against mouse $\beta$ catenin, phospho- $\beta$-catenin ( $p$ - $\beta$-catenin), glyceraldehyde-3phosphate dehydrogenase (GAPDH), and Runx2 (Santa Cruz Biotechnology, Santa Cruz, CA), rabbit Gsk3a/b (Cell Signaling Technology, Danvers, MA), and p84 (AbCam, Cambridge, UK). p84, a nuclear matrix protein, and GAPDH were used as internal controls for nuclear ${ }^{26}$ and total and cytoplasmic proteins, respectively. Secondary anti-mouse peroxidase antibody and chemiluminescent substrate (SuperSignal West Pico, Thermo Fisher Scientific, Waltham, MA) were used to visualize and quantify the signal with a Fujifilm LAS-3000 Imager (Fujifilm, Tokyo, Japan).

\section{Statistical Analysis}

The results are expressed as means \pm SEM. Statistical analysis was performed using two-way analysis of variance. Where significant overall differences were detected by analysis of variance, a Fisher two-tailed, unpaired $t$-test was used to compare differences between the different genotypes or treatments. $P<0.05$ was considered significant. The statistical analysis program used was StatView software version 5.0 (SAS Institute Inc., Cary, NC).

\section{Results}

Effects of Runx2 Expression Levels on Canonical Wnt/ $\beta$-Catenin Signaling Pathway Activity in Vitro and in Vivo

To evaluate the effect of the transcription factor Runx 2 on the activity of the Wnt/ $\beta$-catenin pathway, we crossed TG Runx 2 mice or Runx2 haploinsufficient mice (Runx $2^{+-}$) with the TopGal mouse reporter line. $\beta$-Galactosidase activity was quantified in Runx $2^{+/-} /$TopGal, TG Runx2/TopGal, and WT/ TopGal primary osteoblasts using bioluminescence after 3 days of differentiation (Figure 1A). TG Runx2/TopGal osteoblasts had lower $\beta$-galactosidase activity than their WT counterparts. Accordingly, $\beta$-galactosidase activity was found to be higher in Runx $2^{+/-} /$TopGal primary osteoblasts compared with their WT controls. To further examine the association between Runx 2 and the Wnt/ $\beta$-catenin signaling pathway, we next examined $\beta$-catenin mRNA (Figure 1B) and protein (Figure 1C) levels in primary osteoblasts isolated from WT and TG Runx 2 mice after differentiation in vitro for 6 days. Interestingly, although we did not detect differences in $\beta$-catenin at the mRNA level, $\beta$-catenin protein levels were significantly reduced in TG Runx 2 osteoblasts compared with WT controls. The level of $\beta$-catenin protein was mainly reduced in the nucleus, suggesting that the decreased $\beta$-catenin signaling could be related to a defect in nuclear $\beta$-catenin translocation. $\beta$-Galactosidase activity was also evaluated in vivo by $\mathrm{X}-\mathrm{Gal}$ staining of the calvarial bone (Figure 1D) and long bone sections (Figure 1E) from TG Runx2/TopGal mice and WT/ TopGal control mice. This evaluation confirmed that there is a decrease in $\beta$-catenin transcriptional activity within TG Runx 2 mice. Together, these results provide evidence that alterations in Runx 2 expression levels are associated with changes in the activity of the canonical Wnt/ $\beta$-catenin signaling pathway, suggesting that the $\mathrm{Wnt} / \beta$-catenin signaling pathway may be directly regulated by Runx 2 both in vitro and in vivo.

We next stimulated TG Runx2/TopGal osteoblasts with Wnt3a to assess whether they had normal $\mathrm{Wnt} / \beta$-catenin 
A

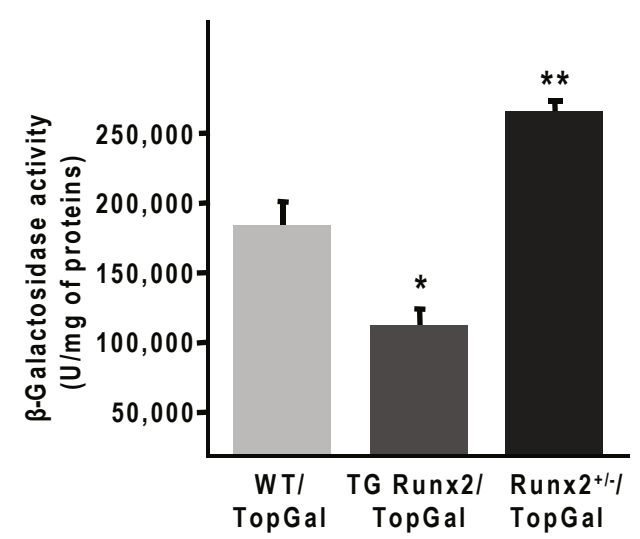

D
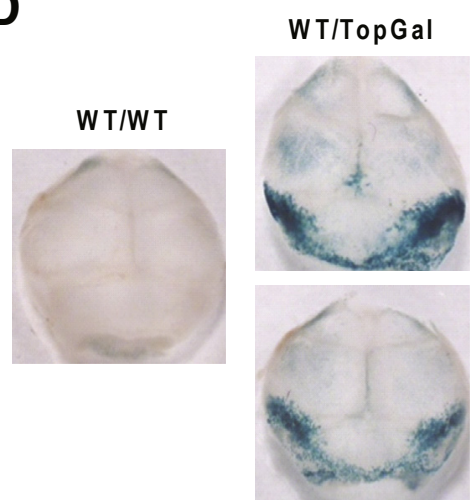

TG Runx2 /TopGal
B

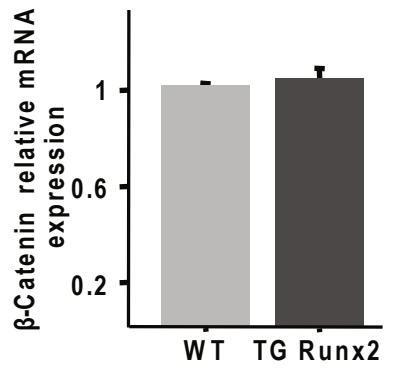

WT/TopGal

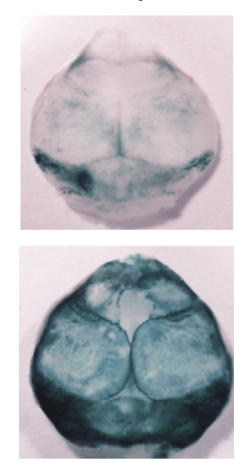

Runx2+l-/TopGal

E
C
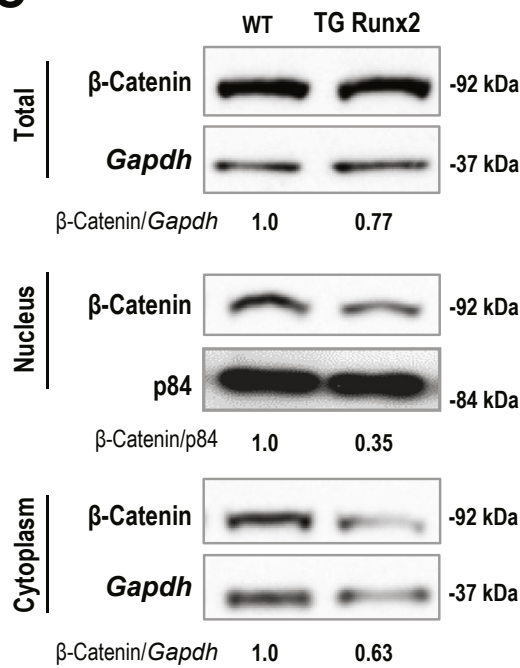
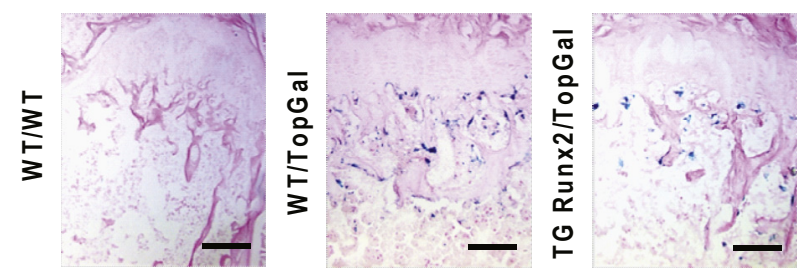

Figure 1 Runx2 overexpression in osteoblast decreases Wnt/ $\beta$-catenin activity in vitro and in vivo. A: Quantification of $\beta$-catenin transcriptional activity was assessed in vitro by $\beta$-galactosidase activity in primary osteoblasts of Runx $2^{+/} /$TopGal, transgenic (TG) Runx2/TopGal, and wild-type (WT)/TopGal mice after 3 days of culture. B: $\beta$-Catenin mRNA expression was quantified by real-time quantitative PCR. C: $\beta$-catenin cellular localization was analyzed by Western blot using total cell extracts and cytoplasmic and nuclear fractions of WT and TG Runx2 primary osteoblasts after 6 days of differentiation. Gapdh and p84 were used as loading controls for cytoplasmic and total fractions and for nuclear fractions, respectively. X-Gal staining was performed on calvarial bone of WT, WT/ TopGal, Runx2 ${ }^{+/}$/TopGal, and TG Runx2/TopGal 3-day-old mice (D) and on coronal sections of femur of WT, WT/TopGal, and TG Runx2/TopGal 3-month-old females (E). Data are presented as means \pm SEM. $n=3 .{ }^{*} P<0.05,{ }^{*} P<0.005$ compared with WT/TopGal. Scale bar $=100 \mu \mathrm{m}$.

signaling. $\beta$-Galactosidase activity was increased at 3 days after Wnt3a stimulation (Figure 2A), which confirmed that TG Runx2 osteoblasts are able to respond to stimulation of the Wnt pathway. This finding also suggested that an inhibitor of the Wnt//-catenin pathway, such as Gsk3b, could be involved in the alteration of $\mathrm{Wnt} / \beta$-catenin signaling observed in TG Runx 2 mice. Western blot analysis of protein extracts taken from primary osteoblastic cells confirmed that Gsk3b levels were higher in TG osteoblasts compared with WT cells after 6 days in culture (Figure 2B). This increase in Gsk3b at the protein level $(+118 \%)$ fits very well with the increase in $p$ - $\beta$-catenin identified in TG Runx 2 osteoblasts compared with WT (Figure 2C) and consequently with the reduction of the total and nuclear $\beta$-catenin protein levels ( $-33 \%$ and $-65 \%$, respectively) (Figure $1 \mathrm{C}$ and Figure $2 \mathrm{~B}$ ).

The higher levels of Gsk $3 \mathrm{~b}$ and $p$ - $\beta$-catenin detected could partly explain the decreased level of nuclear $\beta$-catenin found in Runx2 TG osteoblasts. To explore this further, we determined the effect of $\mathrm{LiCl}$, an inhibitor of Gsk3b, on Wnt/ $\beta$-catenin signaling in osteoblasts isolated from the Runx2 TG mice. ${ }^{27}$ In vitro $\mathrm{LiCl}$ treatment led to the complete rescue of $\beta$-galactosidase activity in TG osteoblastic cells (Figure 2A), associated with a decrease in $p$ - $\beta$-catenin levels (Figure 2C), and increased proliferation (Figure 2D) and alkaline phosphatase activity (Figure 2E). In addition, treatment of TG Runx2 primary osteoblasts with $\mathrm{LiCl}$ resulted in increased mineralized nodule formation in TG Runx2 primary osteoblasts (Figure 2F). To further verify that these effects were due to inhibition of Gsk3b activity, we treated the cells with SB216763, a more specific inhibitor of Gsk3b. Similar to the results observed with $\mathrm{LiCl}$, treatment of the TG Runx2 primary osteoblasts with SB216763 resulted in an increase in cell proliferation and in alkaline phosphatase activity (Figure 2, D and E). Together, these results indicate that the 

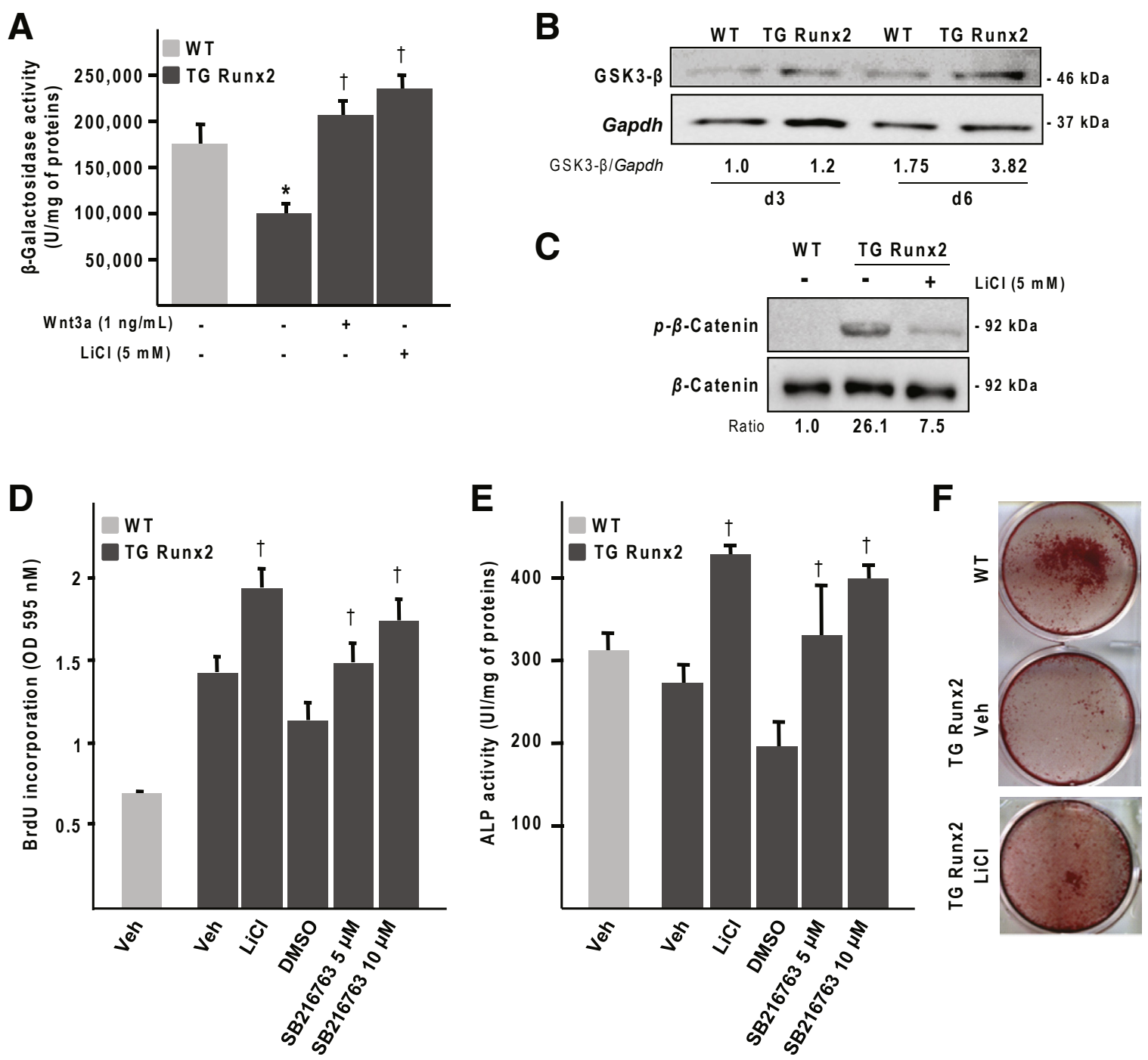

Figure 2 Wnt/ $\beta$-catenin stimulation increases proliferation and restores partial differentiation of transgenic (TG) Runx2 osteoblast in vitro. A: $\beta$-Catenin transcriptional activity was quantified in vitro by $\beta$-galactosidase activity in wild-type (WT)/TopGal and TG Runx2/TopGal primary osteoblasts after 3 days of stimulation in osteogenic medium. The effect of Wnt3a and lithium chloride $(\mathrm{LiCl})$ at the indicated concentration on $\beta$-galactosidase activity was quantified in TG Runx2/TopGal primary osteoblasts. Expression of Gsk3b (B) and phospho- $\beta$-catenin ( $p$ - $\beta$-catenin) (C) were assessed by Western blot on total cellular extract of WT and TG Runx2 primary osteoblasts, respectively, after 3 and 6 days ( $\mathrm{d} 3$ and $\mathrm{d} 6$, respectively) and after 10 days in culture. Gapdh expression was used as a loading control. D: Effect of Gsk3b inhibitors (LiCl and SB216783) on cell proliferation was evaluated in Runx2-overexpressing primary osteoblasts by 5-bromo-2'deoxyuridine (BrdU) incorporation. E: Alkaline phosphatase activity was evaluated in TG Runx2 osteoblast primary culture after 3 days with osteogenic medium with or without $5 \mathrm{mmol} / \mathrm{L} \mathrm{LiCl}$ and 5 and $10 \mu \mathrm{M} \mathrm{SB} 216763$. Proliferation and alkaline phosphatase activity were evaluated in WT cells as control. F: After 15 days, mineralized nodules formation was revealed by Alizarin red staining in WT primary osteoblast cultures and TG Runx2 primary osteoblasts untreated or treated with 5 $\mathrm{mmol} / \mathrm{L} \mathrm{LiCl}$. Effects of LiCl and SB216763 were compared with their respective vehicle (Veh) (saline buffer and dimethyl sulfoxide). Data are expressed as means \pm SEM of one of four independent experiments. $n=5$ wells for each condition. ${ }^{*} P<0.05$ compared with WT; ${ }^{\dagger} P<0.05$ compared with TG Runx2 Veh.

decrease in osteoblast differentiation and activity observed in Runx2 TG mice is related to increased Gsk3b activity, resulting from increased phosphorylation of $\beta$-catenin an inhibition of the $\mathrm{Wnt} / \beta$-catenin pathway.

\section{Osteoclast Differentiation and Activity after LiCl Treatment in TG Runx2 Bone Marrow Culture}

We previously reported that Runx 2 had a complex role in the regulation of bone mass and turnover. ${ }^{19}$ In particular, we found that increased expression of Runx 2 enhanced bone resorption through an effect on osteoblast maturation and cytokine expression in cells of the osteoblastic lineage. ${ }^{19}$ To investigate the contribution of the canonical Wnt signaling to the increased osteoclast differentiation observed in TG Runx2 mice, BM progenitors from 2-month-old TG Runx2 and control mice were induced to differentiate into osteoclast-like cells in vitro in the presence or absence of $\mathrm{LiCl}$. To determine the involvement of the osteoblastic Wnt pathway to osteoclast differentiation, BM progenitor cells were differentiated into osteoclast-like cells using vitamin $\mathrm{D}_{3}$ and ascorbic acid stimulation. As previously described, ${ }^{19}$ 
the number of Trap-positive multinucleated cells in TG Runx2 BM cultures was increased threefold compared with WT BM cultures (Figure 3). Interestingly, $\mathrm{LiCl}$ treatment was found to significantly decrease this effect (Figure 3, A and B). Expression of tartrate-resistant acid phosphatase (Tracp), evaluated by qPCR, was increased in TG Runx2 cultures compared with WT counterparts, and conversely, $\mathrm{LiCl}$ treatment decreased Tracp expression in TG Runx2 BM cells (Figure 3C). The decrease of Tracp expression was consistent with the decrease in the number of Trap-positive multinucleated cells.

The effect of $\mathrm{LiCl}$ treatment on osteoclast activity was then assessed in vitro. To this end, BM cells isolated from WT or TG Runx2 mice were induced to differentiate on dentine slices in the presence of vitamin $\mathrm{D}_{3}$ and ascorbic acid. After 11 days, pit formation was measured. We found that pit numbers and pit surfaces per total surface were twofold higher using TG Runx2 BM cells compared with WT BM cells (Figure 3, D and E). Treatment with $\mathrm{LiCl}$ led to a significant decrease in TG Runx2 osteoclast differentiation, reflected by a marked reduction of pit numbers and pit surfaces per total surface in LiCl-treated cells, without any change in osteoclast activity (Figure 3F). Together, these results indicate that $\mathrm{LiCl}$ reduces osteoclast differentiation in TG Runx2 BM cultures because of the inhibition of the canonical Wnt pathway in osteoblasts. These data also suggest that in vivo osteoclast differentiation is controlled indirectly by cytokines, whose expression is regulated by the canonical Wnt pathway in osteoblasts of Runx2-overexpressing mice.

Next, we quantified expression of Rankl and Opg in vitro by $\mathrm{qPCR}$ in WT and TG Runx2 BM cells induced to differentiate into osteoclast-like cells by vitamin $\mathrm{D}_{3}$ and ascorbic acid. We first confirmed that overexpression of Runx2 in osteoblasts down-regulates Opg and increases Rankl expression in cells of the osteoblastic lineage and thus increases the Rankl/Opg ratio (Figure 3G). Then we analyzed the effect of $\mathrm{LiCl}$ on the expression of the two cytokines in TG Runx2 cells. $\mathrm{LiCl}$ induced a significant decrease in Rankl/Opg ratio in TG Runx2 primary
A

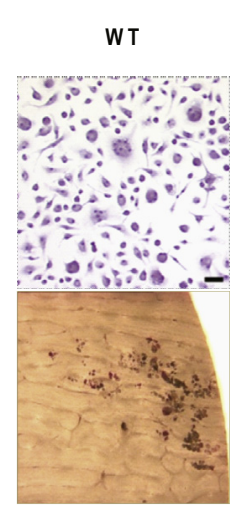

C

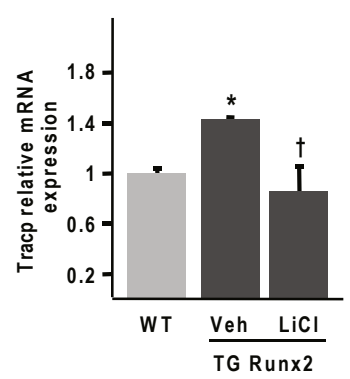

$\mathbf{F}$

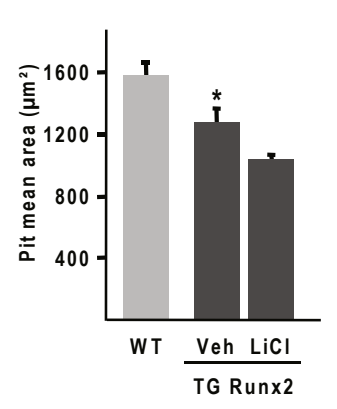

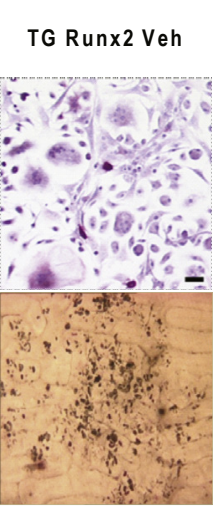
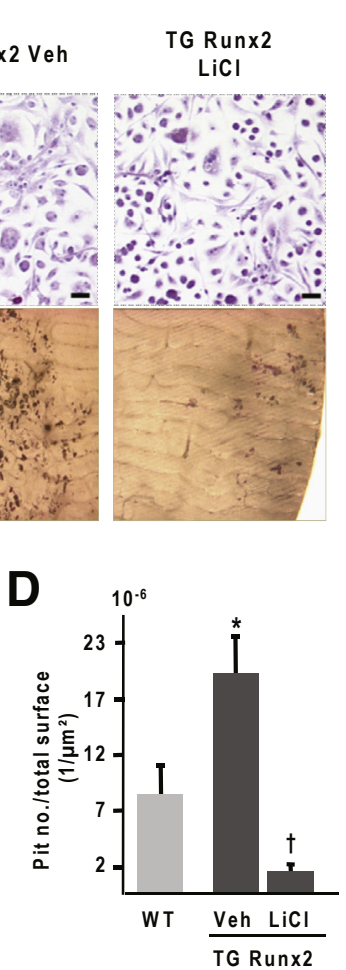

E

G

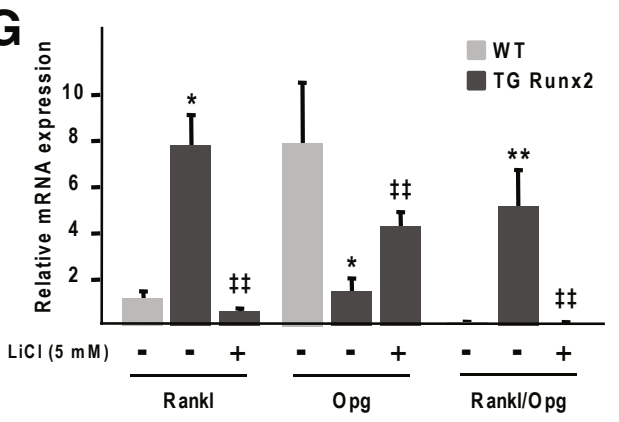

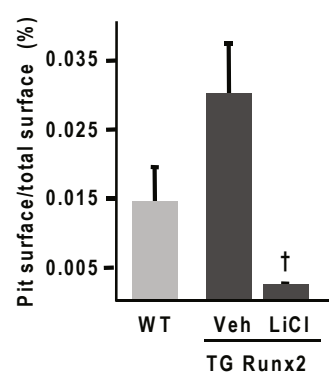

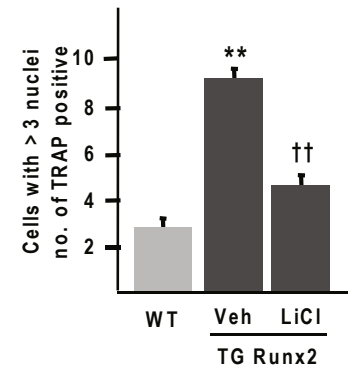

Figure 3 0steoblast-mediated osteoclast differentiation from precursor cells originating from bone marrow (BM) of transgenic (TG) Runx2 mice is affected by lithium chloride ( $\mathrm{LiCl}$ ) treatment in vitro. Osteoclast differentiation from BM precursor cells originating from wild-type (WT) and TG Runx2 mice was induced by $10^{-8} \mathrm{M}$ dihydroxyvitamin $\mathrm{D}_{3}$ and $50 \mu \mathrm{M}$ ascorbic acid in the presence or absence of $5 \mathrm{mmol} / \mathrm{L} \mathrm{LiCl}$ for 11 days of culture. Cells were stained for tartrate-resistant acid phosphatase (Trap) activity (A, top panels), and osteoclast activity was assessed by pit assay on dentin slices and the resorbed areas were stained with India ink (A, lower panels). Trappositive multinucleated cells were counted (B) and Tracp relative expression was measured by real-time quantitative PCR (qPCR) (C). 0steoclast activity was determined by the number of pits (D) and pit surface (E) per total surface and by pit mean area (F). G: Receptor activator of NF- $\kappa \mathrm{B}$ ligand/osteoprotegerin (Rankl/0pg) ratio was determined from quantification of Rankl and Opg expression by $\mathrm{qPCR}$. Data are expressed as means \pm SEM of one of three independent experiments performed in triplicate. ${ }^{*} P<0.05$, ${ }^{*} P<0.005$ compared with $\mathrm{WT} ;{ }^{\dagger} P<0.05$ compared with Runx2 vehicle (Veh); ${ }^{\ddagger \ddagger} P<0.005$ compared with TG Runx2 Veh. Scale bar $=25 \mu \mathrm{m}$ (A). 
osteoblasts due to both a significant decrease in Rankl expression and an significant increase in Opg expression compared with control (Figure 3G). These data suggest that $\mathrm{LiCl}$ treatment reduces the capacity of TG Runx2 osteoblasts to support osteoclast differentiation due to a significant diminution of Rankl/Opg ratio.

\section{Bone Mass and Architecture in Mice that Overexpress Runx2 after LiCl Treatment}

To determine whether activation of the Wnt pathway can reduce bone resorption in vivo, we treated TG Runx 2 mice with
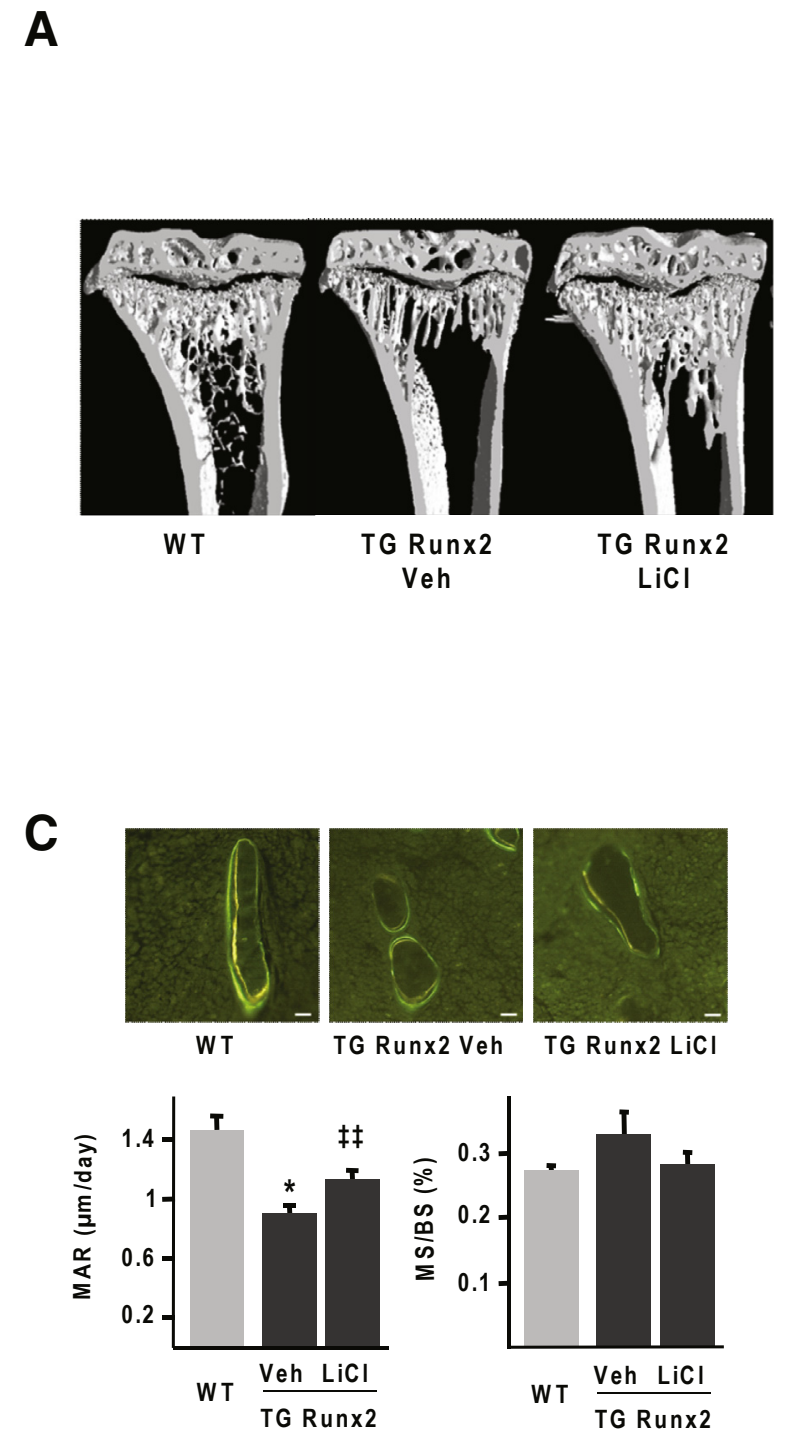

LiCl. We evaluated bone structure by two-dimensional histomorphometry and 3D micro-CT (Figure 4 and Supplemental Table S1). Runx2 TG mice exhibited reduced BV/TV compared with WT littermates. Administration of LiCl restored the bone trabecular volume in TG Runx2 mice to WT levels. Quantification by histomorphometry (Figure $4 \mathrm{~B}$ ) revealed significant increase in BV/TV $(+68 \%)$ and in Tb.N $(+59 \%)$, but no effect on $\mathrm{Tb}$.Th was detected in TG Runx2 mice that received $\mathrm{LiCl}$. In addition, $\mathrm{LiCl}$ treatment strongly reduced Tb.Sp to WT levels in TG Runx2 mice (-43\%). The 3D micro$\mathrm{CT}$ reconstructions confirmed the increase in bone mass in Runx2 TG mice (Figure 4A and Supplemental Table S1). Only
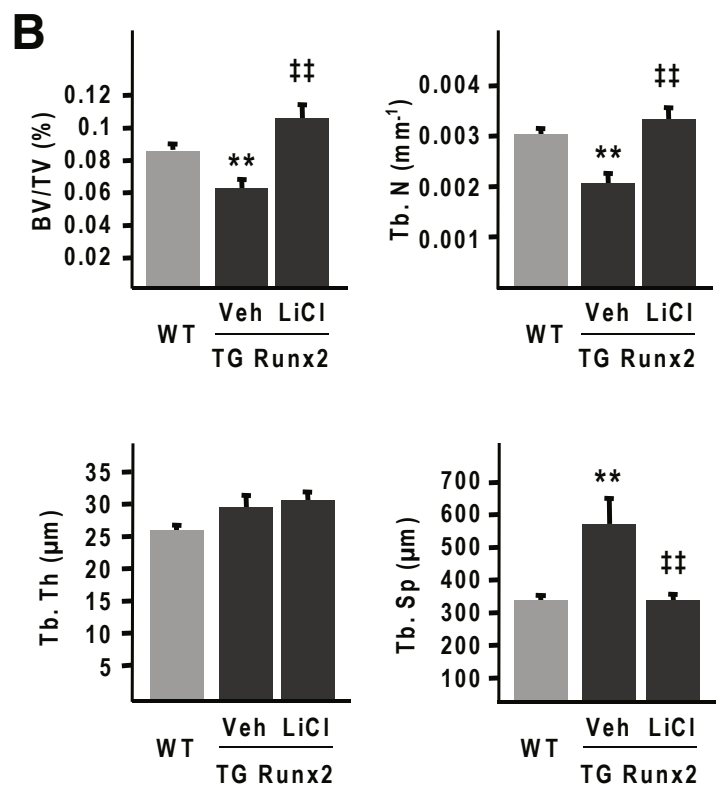

D
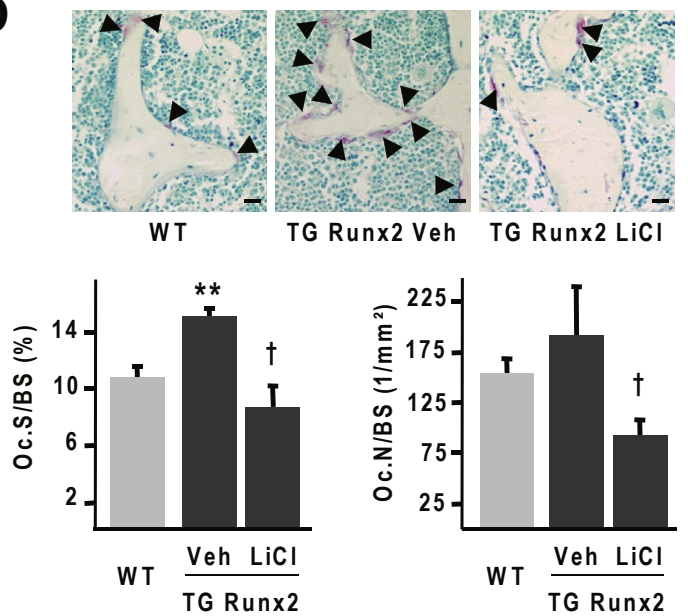

Figure 4 Administration of lithium chloride ( $\mathrm{LiCl}$ ) in transgenic (TG) Runx2 mice restores bone trabecular phenotype. A: Cross-sectional micro-computed tomography reconstruction was performed on distal femur from 3-month-old female wild-type (WT) and TG Runx2 mice treated or not with LiCl. Mice were treated daily for 4 weeks by oral route with vehicle (Veh) (distilled water) or approximately $200 \mathrm{mg} / \mathrm{kg}$ of LiCl. B: Effects of LiCl on bone structures were evaluated on distal femur by histomorphometry. C: Trabecular bone volume (BV/TV), trabecular number (Tb.N), trabecular thickness (Tb.Th), and trabecular separation (Tb.Sp) were measured on femur sections. Fluorochrome labeling of femoral trabecular bone with tetracycline and calcein was performed, and the matrix apposition rate (MAR) and bone mineralizing surface (MS/BS) were quantified. D: Tartrate-resistant acid phosphatase staining was performed on femur longitudinal sections (arrowheads indicate osteoclast), and osteoclast surfaces per bone surface (0c.S/BS) and osteoclast number per bone surface (0c.N/BS) were determined. Data are expressed as means \pm SEM. $n=7$ to $10 .{ }^{*} P<0.05,{ }^{*} P<0.005$ compared with WT; ${ }^{\dagger} P<0.05$ compared with Runx2 Veh; $\ddagger \ddagger P<0.005$ compared with TG Runx2 Veh. Scale bar $=10 \mu \mathrm{m}$ (C and D). 
the cortical thickness, which was significantly thinner in transgenic mice compared with WT mice $(150.8 \pm 6.3 \mu \mathrm{m}$ and $232.5 \pm 7.9 \mu \mathrm{m}$, respectively; $P<0.005$ ), remained unaffected by the $\mathrm{LiCl}$ treatment $(168.3 \pm 4.5 \mu \mathrm{m}$ in TG Runx 2 mice that received $\mathrm{LiCl}$ ). The lack of $\mathrm{LiCl}$ effect on the cortical compartment, which represents approximately $80 \%$ of the long bones, explains why the low BMD in TG Runx2 mice was not affected by $\mathrm{LiCl}$ treatment (Supplemental Figure S2).

qPCR was then performed on the RNA isolated from the long bones of WT and TG Runx2 mice that received vehicle and $\mathrm{LiCl}$ to assess the expression of osteoblast and osteoblast marker genes. The expression of osteocalcin, a marker of mature osteoblasts, that was significantly lower in TG Runx2 long bones compared with WT, was found to be significantly increased in the long bones of TG Runx 2 mice in response to $\mathrm{LiCl}$ (Supplemental Figure S3A). The expression of type I collagen was also increased but to a lesser extent in TG Runx2 mice that received $\mathrm{LiCl}$ compared with control mice (Supplemental Figure S3B). We assessed dynamic bone formation parameters in LiCl-treated and control animals. Consistent with our results in primary osteoblast cultures in vitro, the matrix apposition rate was significantly lower in the trabecular bone of TG Runx 2 mice compared with WT animals and was increased by $\mathrm{LiCl}$ treatment $(+31 \%)$ (Figure $4 \mathrm{C}$ ). There was no significant difference in bone mineralizing surfaces and bone formation rate between WT and TG Runx2 mice, and these parameters remained unaffected by the treatment with $\mathrm{LiCl}$ (unpublished data) (Figure 4C). These results indicate that $\mathrm{LiCl}$ treatment increased osteoblast differentiation and activity in TG Runx2 mice.

Next, the effect of $\mathrm{LiCl}$ treatment on bone resorption in the Runx 2 mice was examined. Both osteoclast surfaces and osteoclast number were higher in TG Runx2 compared with WT mice (Figure 4D). LiCl treatment significantly decreased these parameters in TG Runx 2 mice by $-42 \%$ and $-52 \%$, respectively. However, qPCR analysis of RNA isolated from whole long bones after 1 month of $\mathrm{LiCl}$ treatment indicated that $\mathrm{LiCl}$ treatment had no effect on the expression levels of Tracp, Rankl, and Opg (Supplemental Figure S3, C and D). Together, these data indicate that stimulation of $\mathrm{Wnt} / \beta$-catenin signaling by $\mathrm{LiCl}$ restored the $\mathrm{BV} / \mathrm{TV}$ in Runx2-overexpressing mice mainly via decreased bone resorption.

\section{Discussion}

Runx2 and the Wnt/ $\beta$-catenin signaling pathway play central roles in osteoblast development and bone formation. Our results reveal that the $\mathrm{Wnt} / \beta$-catenin signaling pathway plays a major role in the osteoporotic phenotype of mice that overexpress Runx2, specifically in osteoblasts. Runx $2^{+/-}$- and Runx2overexpressing mice exhibit alterations in $\beta$-catenin transcriptional activity, with decreased $\beta$-catenin osteoblastic activity detected in the Runx2-overexpressing mice and enhanced activity detected in Runx $2^{+/-}$mice compared with WT animals.
Overexpression of Runx2, under the control of a $2.3 \mathrm{~kb}$ Collal promoter sequence, negatively affects the capacity of preosteoblasts to differentiate into fully mature osteoblasts and osteocytes. ${ }^{19}$ Low canonical Wnt pathway activity in Runx2-overexpressing osteoblasts could explain this phenomenon, and, indeed, stimulation of the canonical Wnt pathway rescued the osteoblastic differentiation defect in vitro and in vivo. Although activation of Wnt signaling is essential for early osteoblastic maturation, ${ }^{3}$ late $\mathrm{Wnt} / \beta$ catenin stimulation in cultured osteoblasts inhibits their capacity to form mineralized nodules. ${ }^{28}$ Accordingly, the expression levels of genes implicated in the Wnt pathway decrease during osteoblast maturation, ${ }^{28}$ whereas the expression of Wnt inhibitors, such as Dkk2, increase at the late stage of osteoblast maturation. ${ }^{29}$ The interaction between the Wnt/ $\beta$-catenin signaling pathway and Runx 2 is not well understood, with only a few studies focusing on their possible interplay. Gaur et $\mathrm{al}^{9}$ found that $\mathrm{Wnt} / \beta$-catenin signaling positively regulates Runx 2 expression because of the presence of Tcf response elements in the Runx2 promoter region. In addition, phosphorylation of Runx 2 by Gsk3b leads to Runx 2 inhibition and consequently decreased osteoblastic differentiation in vitro. ${ }^{30}$ Accordingly, Gsk $3 b^{+/-}$ mice have higher Runx2 transcriptional activity than WT littermates, and inhibition of Gsk3b activity by $\mathrm{LiCl}$ increases Runx2 expression in osteoblasts, resulting in osteoblast differentiation. ${ }^{31}$ Conversely, Runx 2 regulates the $\mathrm{Wnt} /$ $\beta$-catenin pathway. For example, Hoeppner et $\mathrm{al}^{32}$ found that Runx2 activates the transcription of an alternative form of Lef1 (Lef1 $\Delta \mathrm{N})$ in osteoblasts. Lefl/Tcf transcription factors mediate a nuclear response to Wnt signals by interacting with $\beta$-catenin. ${ }^{1,2}$ Lef $1 \Delta \mathrm{N}$ expression is induced during late osteoblastogenesis and may be a crucial regulator of terminal differentiation. The regulation of expression of Dkk1, a potent inhibitor of Wnt signaling, during development is Runx2 dependent in bone and teeth. ${ }^{33}$ In the TG Runx2 mice, we found that Lef $1 \Delta \mathrm{N}$ expression is lower than in WT mice, and Dkk1 expression is down-regulated in late stage of osteoblast differentiation (unpublished data). We found that Runx2 overexpression inhibits osteoblast final differentiation, suggesting that the balance between proliferation and differentiation is impaired in transgenic osteoblasts. Therefore, it can be hypothesized that Runx 2 overexpression can alter one or more signaling pathways that regulate osteoblast proliferation, which would explain the high proliferation rate that was detected in vitro. The Wnt canonical pathway is not the only pathway known to stimulate cellular proliferation because the Notch signaling pathway ${ }^{34}$ has also been described to stimulate the proliferation of early osteoblast. ${ }^{35}$ This study presents evidence that Notch can interact directly with Runx 2 and therefore repress its transactivation function, therefore promoting osteoblast differentiation and promoting proliferation.

One possible factor implicated in the down-regulation of the $\beta$-catenin activity by Runx 2 is Gsk $3 b$. We found that both $p$ - $\beta$-catenin and the $p$ - $\beta$-catenin $/ \beta$-catenin ratio are 
increased in TG Runx 2 osteoblasts compared with WT, with both exhibiting reduced levels in response to $\mathrm{LiCl}$ treatment. The increase in Gsk3b may be responsible for the downregulation of the Wnt/ $\beta$-catenin pathway activity through the degradation of $\beta$-catenin. $\mathrm{LiCl}$ was first described as an Gsk3b inhibitor ${ }^{27}$ when used to treat bipolar disease in humans. The effect of $\mathrm{LiCl}$ treatment in bone formation and resorption is unclear and contradictory in the literature. We found that $\mathrm{LiCl}$ has the same effect as the specific Gsk3b inhibitor SB216763 in vitro on both proliferation and differentiation, as measured by alkaline phosphatase activity. We also found that LiCl-induced Gsk3b inhibition is efficient enough to reduce the $p$ - $\beta$-catenin level.

Previous studies using Gsk3b inhibitors in vivo have found differing effects on bone remodeling. ${ }^{36,37}$ Marsell et $\mathrm{al}^{36}$ found that AZD2858 treatment in rats increased bone formation without alteration in bone resorption. Interestingly, $\mathrm{LiCl}$ administration in $\mathrm{C} 57 \mathrm{~B} 1 / 6 \mathrm{~J}$ mice has been reported as an inhibitor in bone resorption and stimulator of bone formation, leading to an increase in bone mass. ${ }^{37}$ Even though these studies agreed on the effect of Gsk3b inhibition on bone formation, its effect on bone resorption remains controversial. This study found that inhibition of Gsk3b by $\mathrm{LiCl}$ strongly reduces resorption in mice that overexpress Runx2 in vivo and in vitro and that in vitro this reduction is correlated with a reduction of the Rankl/Opg ratio in TG Runx2 osteoblasts. The decreased Rank1/Opg ratio caused by Runx 2 has previously been reported. ${ }^{38}$ In our model, the increase in Rankl/Opg ratio may be attributable to the direct transcriptional effect of Runx2 on Rankl and Opg expression levels or to the effect of Runx 2 overexpression on osteoblast differentiation. Indeed, in primary and MC3T3E1 osteoblasts, the decrease in the Rankl/Opg ratio during cell differentiation is mainly due to the decrease in Rankl, rather than the increase in Opg expression. ${ }^{38,39}$ The activation of the $\mathrm{Wnt} / \beta$-catenin pathway in osteoblast precursor cells that overexpress Runx 2 induces a decrease in Rankl expression and an increase in Opg expression. Previous studies have found that activation of the Wnt pathway due to Gsk3b inhibition via $\mathrm{LiCl}$ treatment, or through Wnt3a, led to a decrease in Rankl expression. ${ }^{40,41}$ How Rankl gene expression is inhibited by the $\mathrm{Wnt} / \beta$-catenin pathway is still unclear, but the presence of five consensus Tcf/Lef binding sites on $5^{\prime}$ proximal region of the human $R A N K L$ promoter have been reported. ${ }^{40}$ Moreover, other findings have previously indicated that Dkk-1 and -2 facilitate osteoclastogenesis by enhancing Rankl expression. ${ }^{41}$ Interestingly, we obtained related results when we induced osteoclast differentiation from TG Runx2 BM precursor cells with vitamin $\mathrm{D}_{3}$ in the presence of $\mathrm{LiCl}$. On the other hand, Opg expression can be directly up-regulated by Wnt 3 a in vitro ${ }^{42}$ and conversely can be down-regulated by inhibition of Wnt/ $\beta$-catenin signaling with Dkk-1 and $-2 .{ }^{41}$ In the same line of evidence, mice that express a stabilized form of $\beta$-catenin in osteoblasts were characterized by an osteopetrotic phenotype and by an increase in Opg expression. ${ }^{8}$ In osteoblasts that overexpress Runx2, Gsk3b inhibition also rescued Opg expression. The decrease in Rankl and the increase in Opg expression induced by $\mathrm{LiCl}$ in osteoblasts that overexpress Runx2 can also be explained by the rescue of osteoblast differentiation. Indeed, Rankl is expressed at high levels in less differentiated osteoblasts, and conversely Opg is expressed at high levels in more differentiated osteoblasts.

It is well known that osteocytes are one of the major sources of Rankl in bone. ${ }^{43}$ In TG Runx 2 mice, osteocyte density in the trabecular and cortical bones is strongly reduced. ${ }^{19}$ We cannot completely exclude that the Runx2 transgene is expressed in osteocytes because Rowe's group has already found that the $2.3-\mathrm{Kb}$ Collal promoter is active in these cells. ${ }^{44}$ The conditional inactivation of $\beta$-catenin in osteocytes led to an increase in osteoclast differentiation due to a reduced expression of Opg. ${ }^{45}$ Conversely, osteocytic activation of $\beta$-catenin increases pro-osteoclastogenic cytokine expression. Moreover, elevated bone resorption observed in knock-in daßcat ${ }^{\mathrm{Ot}}$ mice that express a dominant active $\beta$-catenin in osteocytes is explained by the increase in Csf1 and in the Rankl/Opg ratio. ${ }^{46}$ Runx 2 overexpression in osteocytes could have the same effect on Rankl/Opg ratio, which may directly affect bone resorption activity in our model.

The function of the Wnt/ $\beta$-catenin pathway and Gsk3b during osteoclast differentiation is not completely understood. Indeed, Jang et $\mathrm{al}^{47}$ found that inactivation of Gsk3b is essential to osteoclast differentiation induced by Rankl and Nfatc1, but no intrinsic defects in osteoclastic cells were described in Gsk3b ${ }^{+/-}$mice by Kugimiya et al. ${ }^{31}$ In our model, osteoclast differentiation from BM precursor cells induced by Rankl and Csf1 is not affected by inhibition of Gsk3b when Runx2 is overexpressed. This finding indicates that the hyperresorption induced by Runx 2 overexpression is due to the defect in Wnt/B-catenin activity in osteoblasts (unpublished data).

The mechanism by which Runx 2 regulates Gsk $3 b$ is still open for debate, with several mechanisms possibly involved. There are no Runx2-specific OSE2 binding sites in the proximal promoter of the $G s k 3 b$ mouse gene (data not shown). However, this does not mean that Runx2 is not implicated in the regulation of Gsk3b expression at the transcriptional level. Because the effect of Runx2 overexpression on the expression of Gsk3b is only observed after 6 days of culture in the presence of inducers of osteoblast differentiation, an indirect effect of Runx2 remains possible. Other mechanisms, including posttranslational mechanisms, could also be involved.

In conclusion, we found for the first time that Runx 2 is a negative regulator of $\mathrm{Wnt} / \beta$-catenin pathway activity in osteoblasts. We found that Runx2 affects Wnt/ $\beta$-catenin activity mainly through Gsk3b, affecting osteoblast and osteoclast differentiation. Taken together with previous studies, ${ }^{30,31,36,37}$ our data support the conclusion that Gsk3b has an important role in bone metabolism. These new data may also raise questions about the possible role of the 
$\mathrm{Wnt} / \beta$-catenin pathway in the osteoblastic defect observed in cleidocranial dysplasia.

\section{Acknowledgments}

We thank Pierre Marie for helpful discussion, Mary Goldring, Steve Goldring, and Miguel Otero for critical review, and the Laboratoire de Bioingénierie et Biomecanique Ostéo-articulaires for help in micro-CT analysis.

V.G. and C.H. designed the study; V.G. conducted experiments; C.H. collected data; V.G. and C.H. analyzed data; V.G., E.H., and C.H. interpreted data; and V.G. and C.H. wrote the manuscript. V.G. takes the responsibility for the integrity of the data analysis.

\section{Supplemental Data}

Supplemental material for this article can be found at http://dx.doi.org/10.1016/j.ajpath.2016.01.016.

\section{References}

1. Day TF, Guo X, Garrett-Beal L, Yang Y: Wnt/beta-catenin signaling in mesenchymal progenitors controls osteoblast and chondrocyte differentiation during vertebrate skeletogenesis. Dev Cell 2005, 8:739-750

2. Hill TP, Später D, Taketo MM, Birchmeier W, Hartmann C: Canonical Wnt/beta-catenin signaling prevents osteoblasts from differentiating into chondrocytes. Dev Cell 2005, 8:727-738

3. Bennett CN, Longo KA, Wright WS, Suva LJ, Lane TF, Hankenson KD, MacDougald OA: Regulation of osteoblastogenesis and bone mass by Wnt10b. Proc Natl Acad Sci U S A 2005, 102: 3324-3329

4. Wang Y, Li Y-P, Paulson C, Shao J-Z, Zhang X, Wu M, Chen W: Wnt and the Wnt signaling pathway in bone development and disease. Front Biosci 2014, 19:379-407

5. Boudin E, Fijalkowski I, Piters E, Van Hul W: The role of extracellular modulators of canonical Wnt signaling in bone metabolism and diseases. Semin Arthritis Rheum 2013, 43:220-240

6. Gong Y, Slee RB, Fukai N, Rawadi G, Roman-Roman S, Reginato AM, et al: LDL receptor-related protein 5 (LRP5) affects bone accrual and eye development. Cell 2001, 107:513-523

7. Boyden LM, Mao J, Belsky J, Mitzner L, Farhi A, Mitnick MA, Wu D, Insogna K, Lifton RP: High bone density due to a mutation in LDLreceptor-related protein 5. N Engl J Med 2002, 346:1513-1521

8. Glass DA, Bialek P, Ahn JD, Starbuck M, Patel MS, Clevers H, Taketo MM, Long F, McMahon AP, Lang RA, Karsenty G: Canonical Wnt signaling in differentiated osteoblasts controls osteoclast differentiation. Dev Cell 2005, 8:751-764

9. Gaur T, Lengner CJ, Hovhannisyan H, Bhat RA, Bodine PVN, Komm BS, Javed A, van Wijnen AJ, Stein JL, Stein GS, Lian JB: Canonical WNT signaling promotes osteogenesis by directly stimulating Runx2 gene expression. J Biol Chem 2005, 280:33132-33140

10. Komori T, Yagi H, Nomura S, Yamaguchi A, Sasaki K, Deguchi K Shimizu Y, Bronson RT, Gao YH, Inada M, Sato M, Okamoto R, Kitamura Y, Yoshiki S, Kishimoto T: Targeted disruption of Cbfa1 results in a complete lack of bone formation owing to maturational arrest of osteoblasts. Cell 1997, 89:755-764

11. Ducy P, Starbuck M, Priemel M, Shen J, Pinero G, Geoffroy V, Amling M, Karsenty G: A Cbfa1-dependent genetic pathway controls bone formation beyond embryonic development. Genes Dev 1999, 13: $1025-1036$
12. Karsenty G, Ducy P, Starbuck M, Priemel M, Shen J, Geoffroy V, Amling M: Cbfa1 as a regulator of osteoblast differentiation and function. Bone 1999, 25:107-108

13. Ducy P, Zhang R, Geoffroy V, Ridall AL, Karsenty G: Osf2/Cbfa1: a transcriptional activator of osteoblast differentiation. Cell 1997, 89: 747-754

14. Sato M, Morii E, Komori T, Kawahata H, Sugimoto M, Terai K, Shimizu H, Yasui T, Ogihara H, Yasui N, Ochi T, Kitamura Y, Ito Y, Nomura S: Transcriptional regulation of osteopontin gene in vivo by PEBP2alphaA/CBFA1 and ETS1 in the skeletal tissues. Oncogene 1998, 17:1517-1525

15. Kern B, Shen J, Starbuck M, Karsenty G: Cbfa1 contributes to the osteoblast-specific expression of type I collagen genes. J Biol Chem 2001, 276:7101-7107

16. Otto F, Thornell AP, Crompton T, Denzel A, Gilmour KC, Rosewell IR, Stamp GW, Beddington RS, Mundlos S, Olsen BR, Selby PB, Owen MJ: Cbfa1, a candidate gene for cleidocranial dysplasia syndrome, is essential for osteoblast differentiation and bone development. Cell 1997, 89:765-771

17. Mundlos S, Otto F, Mundlos C, Mulliken JB, Aylsworth AS, Albright S, Lindhout D, Cole WG, Henn W, Knoll JH, Owen MJ, Mertelsmann R, Zabel BU, Olsen BR: Mutations involving the transcription factor CBFA1 cause cleidocranial dysplasia. Cell 1997, 89: $773-779$

18. Liu W, Toyosawa S, Furuichi T, Kanatani N, Yoshida C, Liu Y, Himeno M, Narai S, Yamaguchi A, Komori T: Overexpression of Cbfa1 in osteoblasts inhibits osteoblast maturation and causes osteopenia with multiple fractures. J Cell Biol 2001, 155:157-166

19. Geoffroy V, Kneissel M, Fournier B, Boyde A, Matthias P: High bone resorption in adult aging transgenic mice overexpressing cbfa1/runx2 in cells of the osteoblastic lineage. Mol Cell Biol 2002, 22:6222-6233

20. Gao YH, Shinki T, Yuasa T, Kataoka-Enomoto H, Komori T, Suda T, Yamaguchi A: Potential role of cbfa1, an essential transcriptional factor for osteoblast differentiation, in osteoclastogenesis: regulation of mRNA expression of osteoclast differentiation factor (ODF). Biochem Biophys Res Commun 1998, 252:697-702

21. Thirunavukkarasu K, Halladay DL, Miles RR, Yang X, Galvin RJ Chandrasekhar S, Martin TJ, Onyia JE: The osteoblast-specific transcription factor Cbfa1 contributes to the expression of osteoprotegerin, a potent inhibitor of osteoclast differentiation and function. J Biol Chem 2000, 275:25163-25172

22. DasGupta R, Fuchs E: Multiple roles for activated LEF/TCF transcription complexes during hair follicle development and differentiation. Development 1999, 126:4557-4568

23. Parfitt AM, Drezner MK, Glorieux FH, Kanis JA, Malluche H, Meunier PJ, Ott SM, Recker RR: Bone histomorphometry: standardization of nomenclature, symbols, and units: report of the ASBMR Histomorphometry Nomenclature Committee. J Bone Miner Res 1987, 2:595-610

24. Hens JR, Wilson KM, Dann P, Chen X, Horowitz MC, Wysolmerski JJ: TOPGAL mice show that the canonical Wnt signaling pathway is active during bone development and growth and is activated by mechanical loading in vitro. J Bone Miner Res 2005, 20: 1103-1113

25. Haÿ E, Laplantine E, Geoffroy V, Frain M, Kohler T, Müller R, Marie PJ: N-cadherin interacts with axin and LRP5 to negatively regulate Wnt/beta-catenin signaling, osteoblast function, and bone formation. Mol Cell Biol 2009, 29:953-964

26. Zheng L, Annab LA, Afshari CA, Lee WH, Boyer TG: BRCA1 mediates ligand-independent transcriptional repression of the estrogen receptor. Proc Natl Acad Sci U S A 2001, 98:9587-9592

27. Klein PS, Melton DA: A molecular mechanism for the effect of lithium on development. Proc Natl Acad Sci U S A 1996, 93:8455-8459

28. Eijken M, Meijer IMJ, Westbroek I, Koedam M, Chiba H, Uitterlinden AG, Pols HA, van Leeuwen JP: Wnt signaling acts and is regulated in a human osteoblast differentiation dependent manner. J Cell Biochem 2008, 104:568-579 
29. Li X, Liu P, Liu W, Maye P, Zhang J, Zhang Y, Hurley M, Guo C, Boskey A, Sun L, Harris SE, Rowe DW, Ke HZ, Wu D: Dkk2 has a role in terminal osteoblast differentiation and mineralized matrix formation. Nat Genet 2005, 37:945-952

30. Kugimiya F, Kawaguchi H, Ohba S, Kawamura N, Hirata M, Chikuda H, Azuma Y, Woodgett JR, Nakamura K, Chung U: GSK-3beta controls osteogenesis through regulating Runx2 activity. PLoS One 2007, 2:e837

31. Arioka M, Takahashi-Yanaga F, Sasaki M, Yoshihara T, Morimoto S, Hirata M, Mori Y, Sasaguri T: Acceleration of bone regeneration by local application of lithium: Wnt signal-mediated osteoblastogenesis and Wnt signal-independent suppression of osteoclastogenesis. Biochem Pharmacol 2014, 90:397-405

32. Hoeppner LH, Secreto F, Jensen ED, Li X, Kahler RA, Westendorf JJ: Runx 2 and bone morphogenic protein 2 regulate the expression of an alternative Lef1 transcript during osteoblast maturation. J Cell Physiol 2009, 221:480-489

33. James MJ, Järvinen E, Wang X-P, Thesleff I: Different roles of Runx2 during early neural crest-derived bone and tooth development. J Bone Miner Res 2006, 21:1034-1044

34. Cheng C, Yeh J, Fan T-P, Smith SK, Charnock-Jones DS: Wnt5a-mediated non-canonical Wnt signalling regulates human endothelial cell proliferation and migration. Biochem Biophys Res Commun 2008, 365:285-290

35. Engin F, Yao Z, Yang T, Zhou G, Bertin T, Jiang MM, Chen Y, Wang L, Zheng H, Sutton RE, Boyce BF, Lee B: Dimorphic effects of Notch signaling in bone homeostasis. Nat Med 2008, 14:299-305

36. Marsell R, Sisask G, Nilsson Y, Sundgren-Andersson AK, Andersson U, Larsson S, Nilsson O, Ljunggren O, Jonsson KB: GSK-3 inhibition by an orally active small molecule increases bone mass in rats. Bone 2012, 50:619-627

37. Clément-Lacroix P, Ai M, Morvan F, Roman-Roman S, Vayssière B, Belleville C, Estrera K, Warman ML, Baron R, Rawadi G: Lrp5independent activation of Wnt signaling by lithium chloride increases bone formation and bone mass in mice. Proc Natl Acad Sci U S A 2005, 102:17406-17411

38. Deyama Y, Takeyama S, Koshikawa M, Shirai Y, Yoshimura Y, Nishikata M, Suzuki K, Matsumoto A: Osteoblast maturation suppressed osteoclastogenesis in coculture with bone marrow cells. Biochem Biophys Res Commun 2000, 274:249-254

39. Thomas GP, Baker SU, Eisman JA, Gardiner EM: Changing RANKL/OPG mRNA expression in differentiating murine primary osteoblasts. J Endocrinol 2001, 170:451-460

40. Spencer GJ, Utting JC, Etheridge SL, Arnett TR, Genever PG: Wnt signalling in osteoblasts regulates expression of the receptor activator of NFkappaB ligand and inhibits osteoclastogenesis in vitro. J Cell Sci 2006, 119:1283-1296

41. Fujita K, Janz S: Attenuation of WNT signaling by DKK-1 and -2 regulates BMP2-induced osteoblast differentiation and expression of OPG, RANKL and M-CSF. Mol Cancer 2007, 6:71

42. Willert J, Epping M, Pollack JR, Brown PO, Nusse R: A transcriptional response to Wnt protein in human embryonic carcinoma cells. BMC Dev Biol 2002, 2:8

43. Nakashima T, Hayashi M, Fukunaga T, Kurata K, Oh-Hora M, Feng JQ, Bonewald LF, Kodama T, Wutz A, Wagner EF, Penninger JM, Takayanagi H: Evidence for osteocyte regulation of bone homeostasis through RANKL expression. Nat Med 2011, 17: $1231-1234$

44. Marijanović I, Jiang X, Kronenberg MS, Stover ML, Erceg I, Lichtler AC, Rowe DW: Dual reporter transgene driven by 2.3Colla1 promoter is active in differentiated osteoblasts. Croat Med J 2003, 44: 412-417

45. Kramer I, Halleux C, Keller H, Pegurri M, Gooi JH, Weber PB, Feng JQ, Bonewald LF, Kneissel M: Osteocyte Wnt/beta-catenin signaling is required for normal bone homeostasis. Mol Cell Biol 2010, 30:3071-3085

46. Tu X, Delgado-Calle J, Condon KW, Maycas M, Zhang H, Carlesso N Taketo MM, Burr DB, Plotkin LI, Bellido T: Osteocytes mediate the anabolic actions of canonical Wnt/ $\beta$-catenin signaling in bone. Proc Natl Acad Sci U S A 2015, 112:E478-E486

47. Jang HD, Shin JH, Park DR, Hong JH, Yoon K, Ko R, Ko C-Y, Kim H-S, Jeong D, Kim N, Lee SY: Inactivation of glycogen synthase kinase- $3 \beta$ is required for osteoclast differentiation. J Biol Chem 2011 , 286:39043-39050 